\title{
Fairness of seat allocation methods in proportional representation
}

\author{
L van Eck SE Visagi $\quad$ HC de Kock* \\ Received: 26 August 2005; Revised: 27 October 2005; Accepted: 4 November 2005
}

\begin{abstract}
In this paper the fairness of some methods of allocating seats in a proportional representation (PR) voting system is investigated. Different PR systems are in use throughout the democratic world, but the primary focus here is the method used in South Africa, namely the largest remainder method with a Droop quota. It is shown that as the number of parties increases, the number of lost votes (votes not used to allocate seats) increases when using this method. Other existing allocation methods are discussed and compared with each other as well as with three optimisation methods (based on mathematical programming) introduced in this paper. Applying these mathematical programming methods results in allocations that are more fair than the existing methods of seat allocation, if South African voting data are used. These mathematical models attempt to minimise a number of different measures of the deviation between the actual percentage of votes received and the percentage of seats allocated to a certain party. Ideally this deviation should be zero, but due to the discrete nature of seats this is virtually impossible to achieve.
\end{abstract}

Key words: Proportional representation, seat allocation, integer programming, quadratic programming.

\section{Introduction}

Proportional representation (PR) systems are a family of voting systems used in multiplewinner elections. The principle behind PR elections is that every vote deserves its representation in government and each political party involved should be represented in the legislature in proportion to its strength in the electorate. Essentially, this means that each party should receive the same percentage of representation as the percentage of votes received. All PR systems set out to achieve this objective. In typical PR systems there are multi-member districts [1]. These districts may vary in size, as is the case in South Africa, where no two of the nine provinces are equal in size. Seats in these districts are

\footnotetext{
${ }^{*}$ Department of Logistics, University of Stellenbosch, Private bag X1, Matieland, 7602, Republic of South Africa

${ }^{\dagger}$ Corresponding author: Department of Logistics, University of Stellenbosch, Private bag X1, Matieland, 7602, Republic of South Africa, email: svisagie@sun.ac.za
} 
allocated proportionately to the percentage of votes received in that particular district. Thus, if a party receives $30 \%$ of the votes, 3 out of 10 seats should be allocated to that party. The challenge in PR systems is to translate the electoral votes into seats in the same proportion as the actual votes received. Seat allocations are integer numbers, whilst the number of votes may be considered as continuous quantities in comparison to the number of seats. Therefore, the translation of the number of votes into the number of seats nearly always involves adjustment methods. The objective from an operations research point of view is to minimise some measure of the deviation between the actual percentage of votes cast and the percentage of seats allocated to the different parties.

The remainder of this paper is structured as follows. A brief discussion of commonly used methods to allocate seats in PR systems follows in $\$ 2$. In $\$ 3$ the method used in South Africa is investigated in some detail. Results from simulations are provided to support the two main theorems describing the effect of an increase in the number of parties on the total absolute deviation of a district. Three mathematical programming models based on mixed integer programming are introduced in \$4. A comparative case study, where different methods are applied to the actual South African electoral results from the 1999 and 2004 national elections, is discussed in $\$ 5$. Finally, in $\$ 6$ brief concluding remarks on the results obtained and ideas for further study are given.

\section{A short overview of existing seat allocation methods}

Different methods of allocating seats after votes have been counted are in use all over the democratic world. The vast majority of democratic countries use some form of proportional representation. Some of the few exceptions are France, the UK and some of its former colonies, such as the USA, Canada and India [2]. All the different PR systems used today fall into one of two categories, namely highest average (or divisor) methods or largest remainder (or quota) methods [6].

\subsection{Highest averages methods}

A highest average method requires that the number of votes for each party is divided successively by a series of divisors. Seats are then allocated to parties with the highest resulting quotient until all the seats available are allocated. Two highest average methods, namely the d'Hondt method and the Sainte-Laguë method, are the most commonly used [9] and are considered in this paper.

\subsubsection{The d'Hondt method}

Some of the countries using the d'Hondt method are Argentina, Austria, Bulgaria, Chile, Croatia, Finland, Israel, The Netherlands, Poland, Portugal, Spain and Turkey [15]. The method works as follows. Successive quotients for each party are calculated. The formula for the quotient is given by $\frac{V_{i}}{s_{i}+1}$, where $V_{i}$ is the total number of votes received in favour of party $i$ and $s_{i}$ is the number of seats that has been allocated to a specific party (party $i$ ) so far. Initially $s_{i}$ is set to zero for all the parties. The party with the highest quotient 
is allocated the next seat and the quotient is recalculated with $s_{i}$ increased by one. This process is repeated until all the seats have been allocated. d'Hondt's method to allocate 6 seats to 5 parties is shown in Table 1. The numbers in bold indicate where the seat has been allocated.

\begin{tabular}{|c|c|c|c|c|c|c|}
\hline \multicolumn{7}{|c|}{ Seat allocation } \\
\hline & Party A & Party B & Party C & Party D & Party E & Party F \\
\hline$V_{i}$ & 40000 & 23000 & 16500 & 13000 & 9000 & 3200 \\
\hline $1^{\text {st }}$ seat & 40000 & 23000 & 16500 & 13000 & 9000 & 3200 \\
\hline $2^{\text {nd }}$ seat & 20000 & 23000 & 16500 & 13000 & 9000 & 3200 \\
\hline $3^{\text {rd }}$ seat & 20000 & 11500 & 16500 & 13000 & 9000 & 3200 \\
\hline $4^{\text {th }}$ seat & 13333 & 11500 & 16500 & 13000 & 9000 & 3200 \\
\hline $5^{\text {th }}$ seat & 13333 & 11500 & 8250 & 13000 & 9000 & 3200 \\
\hline $6^{\text {th }}$ seat & 10000 & 11500 & 8250 & 13000 & 9000 & 3200 \\
\hline Total seats & 3 & 1 & 1 & 1 & 0 & 0 \\
\hline
\end{tabular}

Table 1: An illustration of d'Hondt's method of allocating seats proportional to votes.

\subsubsection{The Sainte-Laguë method}

Sainte-Laguë's method is also known as Webster's method or the divisor method with standard rounding. This method is used in New Zealand, Norway, Sweden, Denmark, Bosnia and Herzegovina, Latvia, Hamburg and Bremen [17. The successive quotients for each party are calculated similar to d'Hondt's method, but the formula $\frac{V_{i}}{2 s_{i}+1}$ is used instead. In this formula $V_{i}$ is the total number of votes cast in favour of party $i$ and $s_{i}$ is the number of seats that has been allocated to party $i$ so far. If no seats have been allocated, then $s_{i}=0$ for all the parties. The party with the highest quotient is allocated the next seat and the quotient is recalculated for that party with the value of $s_{i}$ increased by one. This process is repeated until all the seats have been allocated. Some countries, such as Sweden and Denmark, use a modified version by replacing the first divisor with 1.4 [17. An illustration of how the seats are allocated by means of the Sainte-Lague method can be found in Table 2. The same votes as in Table 1 are used. The seat allocation with the modified version of Sainte-Laguë's method is given in Table 3 . The modified version of the Sainte-Laguë method gives exactly the same seat allocation as d'Hondt's method, while the normal Sainte-Laguë method gives a different allocation of the seats.

\begin{tabular}{crrrrrr}
\hline & \multicolumn{9}{c}{ Seat allocation } & & \\
& Party A & Party B & Party C & Party D & Party E & Party F \\
\hline$V_{i}$ & 40000 & 23000 & 16500 & 13000 & 9000 & 3200 \\
$1^{\text {st }}$ seat & $\mathbf{4 0 0 0 0}$ & 23000 & 16500 & 13000 & 9000 & 3200 \\
$2^{\text {nd }}$ seat & 13333 & $\mathbf{2 3 0 0 0}$ & 16500 & 13000 & 9000 & 3200 \\
$3^{\text {rd }}$ seat & 13333 & 7667 & $\mathbf{1 6 5 0 0}$ & 13000 & 9000 & 3200 \\
$4^{\text {th }}$ seat & $\mathbf{1 3 3 3 3}$ & 7667 & 5500 & 13000 & 9000 & 3200 \\
$5^{\text {th }}$ seat & 8000 & 7667 & 5500 & $\mathbf{1 3 0 0 0}$ & 9000 & 3200 \\
$6^{\text {th }}$ seat & 8000 & 7667 & 5500 & 4333 & $\mathbf{9 0 0 0}$ & 3200 \\
\hline Total seats & 2 & 1 & 1 & 1 & 1 & 0 \\
\hline
\end{tabular}

Table 2: An example of the seat allocation by means of the Sainte-Laguë method. 


\begin{tabular}{crrrrrr}
\hline & \multicolumn{5}{c}{ Seat allocation } \\
& Party A & Party B & Party C & Party D & Party E & Party F \\
\hline$V_{i}$ & 40000 & 23000 & 16500 & 13000 & 9000 & 3200 \\
$1^{\text {st }}$ seat & $\mathbf{2 8 5 7 1}$ & 16429 & 11786 & 9286 & 6429 & 2286 \\
$2^{\text {nd }}$ seat & 13333 & $\mathbf{1 6 4 2 9}$ & 11786 & 9286 & 6429 & 2286 \\
$3^{\text {rd }}$ seat & $\mathbf{1 3 3 3 3}$ & 7667 & 11786 & 9286 & 6429 & 2286 \\
$4^{\text {th }}$ seat & 8000 & 7667 & $\mathbf{1 1 7 8 6}$ & 9286 & 6429 & 2286 \\
$5^{\text {th }}$ seat & 8000 & 7667 & 5500 & $\mathbf{9 2 8 6}$ & 6429 & 2286 \\
$6^{\text {th }}$ seat & $\mathbf{8 0 0 0}$ & 7667 & 5500 & 4333 & 6429 & 2286 \\
\hline Total seats & 3 & 1 & 1 & 1 & 0 & 0 \\
\hline
\end{tabular}

Table 3: An example of the seat allocation by means of the modified Sainte-Laguë method.

\section{$2.2 \quad$ Largest remainder methods}

The largest remainder methods (LR methods) are the other class of allocation methods. This method requires that each party's votes are divided by a quota, which represents the number of votes required for a seat. A notional number of seats is given to each party. This seat allocation typically includes an integer part and a remainder part. Each party receives the number of seats equal to the integer value. Generally this will leave some seats unallocated. The parties are then ranked on the basis of descending remainders. The parties with the largest remainders are allocated one additional seat until all the seats have been allocated. Several possibilities exist to determine the quota. The Hare quota and the Droop quota are the most common [16].

The Hamilton method of allocation is specifically defined as using the Hare quota. It is used in Namibia and Hong Kong [16]. The Hare quota, $H_{q}$, is defined as

$$
H_{q}=\frac{\text { total votes }}{\text { total seats }}
$$

The Droop quota, $D_{q}$, is applied to elections in South Africa and is defined as

$$
D_{q}=1+\left\lfloor\frac{\text { total votes }}{1+\text { total seats }}\right\rfloor,
$$

where $\lfloor x\rfloor$ denotes the largest integer smaller than or equal to $x$.

The Imperiali quota, $I_{q}$, is a third kind of quota, but is rarely used since it may happen that more candidates are elected than the number of seats that are available when using this method. This quota is given by

$$
I_{q}=\frac{\text { total votes }}{2+\text { total seats }} .
$$

Examples to illustrate the working of the LR methods (using Droop and Hare quotas respectively) are shown in Tables 4 and 5 . In both cases ten seats are to be allocated to six parties.

Schuster et al. (2003) indicate in their study that the d'Hondt method is biased towards larger parties, while Sainte-Laguë is considered less biased. The difference in seat allocation 


\begin{tabular}{lrrrrrrrr}
\hline & \multicolumn{9}{c}{ Seat allocation } & & & \\
& Party A & Party B & Party C & Party D & Party E & Party F & Total \\
\hline$V_{i}$ & 40000 & 23000 & 16500 & 13000 & 9000 & 3200 & 104700 \\
\hline Votes / quota & 3.820 & 2.197 & 1.576 & 1.242 & 0.860 & 0.306 & \\
\hline Automatic seats & 3 & 2 & 1 & 1 & 0 & 0 & 7 \\
\hline Remainder & 0.820 & 0.197 & 0.576 & 0.242 & 0.860 & 0.306 & \\
\hline Largest rem. seats & 1 & 0 & 1 & 0 & 1 & 0 & 3 \\
\hline Total seats & 4 & 2 & 2 & 1 & 1 & 0 & 10 \\
\hline
\end{tabular}

Table 4: Allocation of seats using the Hare quota. In this table 10 seats should be allocated, which implies a Hare quota of 10470 .

\begin{tabular}{lrrrrrrrr}
\hline & \multicolumn{9}{c}{ Seat allocation } & & & \\
& Party A & Party B & Party C & Party D & Party E & Party F & Total \\
\hline$V_{i}$ & 40000 & 23000 & 16500 & 13000 & 9000 & 3200 & 104700 \\
\hline Votes / quota & 4.202 & 2.416 & 1.733 & 1.366 & 0.945 & 0.336 & \\
\hline Automatic seats & 4 & 2 & 1 & 1 & 0 & 0 & 8 \\
\hline Remainder & 0.202 & 0.416 & 0.733 & 0.366 & 0.945 & 0.336 & \\
\hline Largest rem. seats & 0 & 0 & 1 & 0 & 1 & 0 & 2 \\
\hline Total seats & 4 & 2 & 2 & 1 & 1 & 0 & 10 \\
\hline
\end{tabular}

Table 5: Allocation of seats using the Droop quota. In this table 10 seats must be allocated, which implies a Droop quota of 9519.

can be observed in the respective examples, where d'Hondt's allocated 3 seats to the largest party compared to the normal Sainte-Laguë method which allocated two seats. The modified version of the Sainte-Laguë method, like d'Hondt's method, tends to favour the largest party, as seen in the example. Schuster et al. (2003) also revealed that, contrary to popular belief, LR methods as a family are relatively unbiased towards any party. Their study, however, concentrates on the LR method using the Hare quota. Furthermore, Schuster et al. (2003) mention that the different quotas tend to be biased towards some parties in certain situations, but on average no party gains a significant advantage or disadvantage by using any of these methods. The topics of fairness and bias of allocation methods have not been studied in great detail in the operations research literature. The two papers available are by Ernst (1994) and Oyama \& Ichimori (1995).

\section{Allocation of seats in South Africa}

Currently, South Africa uses the LR method with the Droop quota (LRMD) [3, 4]. Recent elections in South Africa have been dominated by one party, which logically received the majority of the seats. Another typical phenomenon in South African elections is the large number of parties participating in the elections. The majority of these parties receive almost no votes, i.e. less than $1 \%$ of the votes. Furthermore, there are almost no medium- 
sized parties, i.e. parties with approximately $20 \%$ of the votes. It is known from other experimental studies that most of the known allocation methods tend (in various degrees) to be unfair and usually favour the larger parties [13. It remains a question whether this pattern of voting influences the fairness of seat allocation. Another question that is often raised in the South African media is whether the large number of small parties favours the larger party or not. To answer these questions a closer investigation of the LR method using the Droop quota is necessary.

From (1) it follows that

$$
D_{q}=1+\left\lfloor\frac{V}{1+S}\right\rfloor
$$

where $D_{q}$ is the Droop quota, $V$ is the total number of votes and $S$ is the total number of seats. The number of automatic seats $m_{i}$ for party $i$ is then given by

$$
m_{i}=\left\lfloor\frac{v_{i}}{D_{q}}\right\rfloor
$$

where $v_{i}$ is the number votes for party $i$. If

$$
\sum_{i=1}^{P} m_{i}=M<S
$$

then the last $S-M=R$ seats are allocated to the $R$ parties with the largest remainders. The following theorem shows that, in general, the potential number of seats allocated from the remainders $(R)$ increases as the number of parties increases.

\section{Theorem 1}

The maximum number of seats allocated from the remainder, $R$, increases as the number of parties increases, that is

$$
0 \lesssim R \lesssim P-2
$$

where $P$ is the number of parties and $\lesssim$ denotes approximately less than or equal to.

Proof: From (2), the number of seats automatically allocated is

$$
m_{i}=\left\lfloor\frac{v_{i}}{D_{q}}\right\rfloor .
$$

It follows that

$$
\frac{v_{i}}{D_{q}}=m_{i}+F_{i}, \quad i=1, \ldots, P
$$

and

$$
0 \leq F_{i}<1, \quad i=1, \ldots, P .
$$

If the sum over all parties is taken in (3), it follows that

$$
\frac{1}{D_{q}} \sum_{i=1}^{P} v_{i}=\frac{V}{D_{q}}=\sum_{i=1}^{P} m_{i}+\sum_{i=1}^{P} F_{i} .
$$


From (1) we can show that

$$
\left(\frac{V}{S+1}\right)+1 \geq D_{q} \geq \frac{V}{S+1}
$$

Equation (5) may be rewritten as

$$
(S+1) \geq \frac{V}{D_{q}} \geq(S+1)\left(1-\frac{1}{D_{q}}\right) .
$$

If $D_{q}$ is sufficiently large (this means that $V$ must be substantially larger than $S$, which is usually the case), it means that

$$
\frac{V}{D_{q}} \approx S+1
$$

This result implies that

$$
\sum_{i=1}^{P} m_{i}+\sum_{i=1}^{P} F_{i} \approx S+1,
$$

which means that $\sum_{i=1}^{P} F_{i}$ will approximately be an integer value. If (4) is summed over all the parties and used together with (6), the approximate bounds for the sum of the remainders are given by

$$
1 \lesssim \sum_{i=1}^{P} F_{i} \lesssim P-1 .
$$

In general we know that $M+R=S$. If this is used in conjunction with (6), it follows that

$$
\sum_{i=1}^{P} F_{i} \approx R+1
$$

By substituting (8) back into (7) the result stated in the theorem is obtained as

$$
0 \lesssim R \lesssim P-2
$$

A simulation was performed for 6000 random elections to determine the probability that a certain number of seats will be unallocated for a certain number of parties. In the simulation 100 seats were allocated using LRMD. It is interesting that the probability of $R$ taking on a certain value is not the same, i.e. $P(R=1) \neq P(R=2) \neq P(R=3) \ldots$ From the simulation it follows that $R$ has a hypergeometric distribution with an expected value of

$$
E(R)=\frac{P-2}{2}
$$

This implies that the expected number of remainders, $A_{r}$, not used to allocate seats is given by

$$
E\left(A_{r}\right)=P-\frac{P-2}{2}
$$

This result hints that, on average, the number of lost votes increases with an increase in the number of parties. Thus, on average, more votes will not be used to allocate seats 


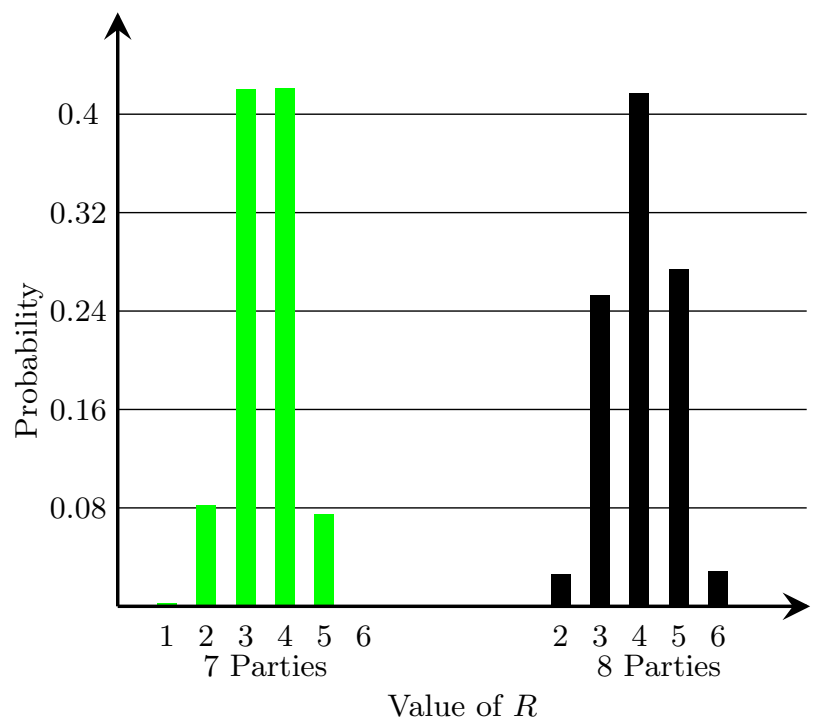

Figure 1: The distribution of the number of seats allocated from the remainders.

if the total number of votes is scattered over more parties. This result is formalised in Theorem 2 and is indeed echoed by the simulation results shown in Figure 1. It is more convenient to express the number of lost votes, i.e. votes that are not used to allocate seats, in terms of the number of lost seats. The basic problem that arises when working with lost votes is that the weight (influence) of one vote differs with respect to the total number of votes counted. This gives rise to the term vote-seats. The number of vote-seats is defined as the number of lost votes divided by the quota.

\section{Theorem 2}

$$
1 \leq \text { maximum number of vote-seats } \leq \begin{cases}\frac{(k+1)^{2}}{2 k+1} & \text { if } P=2 k+1 \\ \frac{k+1}{2} & \text { if } P=2 k\end{cases}
$$

for some $k \in \mathbb{N}$, where vote-seats is the number of lost votes expressed in terms of seats.

Proof: From (8) it follows that the average fraction (remainder) is approximated by

$$
\frac{1}{P}\left[\sum_{i=1}^{P} F_{i}\right] \approx \frac{R+1}{P},
$$

where $P$ represents the number of parties, or in this case the maximum number of remainders, and $R$ is the number of seats allocated using the remainders. The maximum number of vote-seats (not allocated because the remainders are too small) as a function of $R$ is then given by

$$
f(R)=(P-R)\left(\frac{R+1}{P}\right) .
$$


The actual number of vote-seats will always be less than or equal to $f(R)$. The first and second derivatives of $f(R)$ are

$$
f^{\prime}(R)=-\frac{1}{P}(2 R-P+1) \quad \text { and } \quad f^{\prime \prime}(R)=-\frac{2}{P},
$$

respectively. The second derivative will always be negative. The maximum of this function will thus occur at

$$
R=\frac{P-1}{2}
$$

if both $P$ and $R$ are integers. Different results are obtained when $P$ is an odd or an even number.

$P$ odd: $\quad$ In this case $P$ may be expressed as $P=2 k+1$ for some $k \in \mathbb{N}$. The function $f(R)$ will thus achieve a maximum at

$$
R=\frac{2 k+1-1}{2}=k \text {. }
$$

The corresponding maximum number of vote-seats is given by

$$
f(R)=\frac{(k+1)^{2}}{2 k+1}
$$

$P$ even: $\quad$ In this case $P$ may be expressed as $P=2 k$ for some $k \in \mathbb{N}$. The function $f(R)$ will thus achieve a maximum at two values, namely

$$
R=\frac{2 k-1}{2} \pm \frac{1}{2}
$$

both with a corresponding maximum value of

$$
f(R)=\frac{k+1}{2}
$$

Of course, the average number of lost votes will only be the number of vote-seats multiplied by the quota, that is

$$
f(R) \times\left(\left\lfloor\frac{V}{S+1}\right\rfloor+1\right)
$$

A second simulation was implemented to determine the average number of vote-seats, as well as the maximum number of vote-seats, and how these values compares to the theoretical maximum as stated Theorem 2. Once again 6000 simulation runs (elections) were simulated to obtain the results.

It may be seen from the data in Figure 2 that the average number of lost votes does not increase proportionately to the theoretical maximum. Where there is a small number of parties, the average number of lost votes is very near to the theoretical maximum. As the number of parties increases, the gap widens between these two variables. 


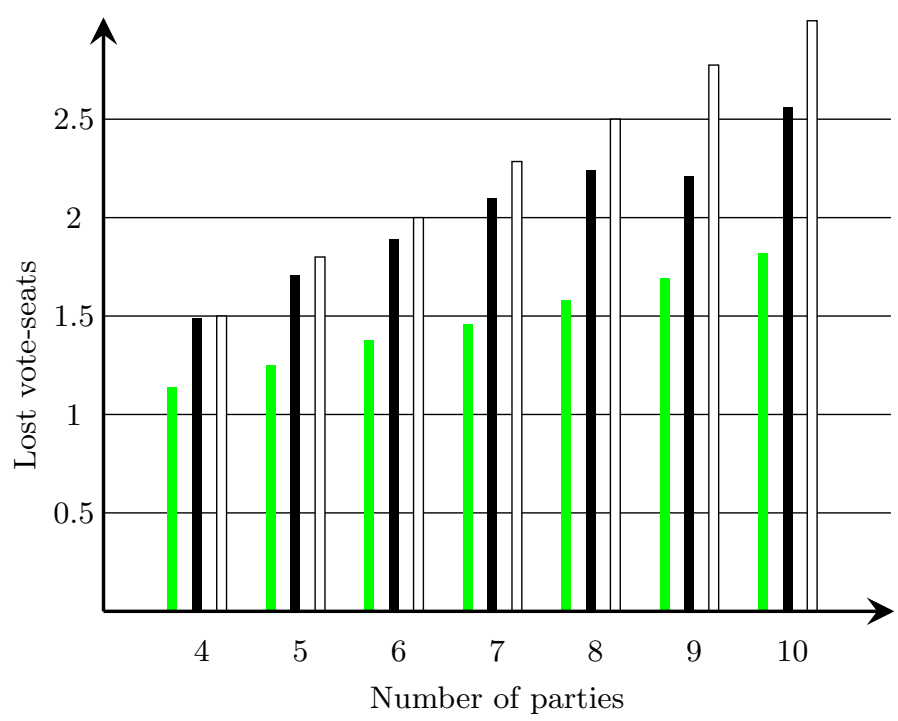

Figure 2: Average number of vote-seats versus the number of parties. The grey bar represents the average number of vote-seats and the black bar the maximum number of lost votes found for the 6000 simulation runs. The white bar gives the theoretical maximum that follows from Theorem 2.

\section{Mathematical programming models for seat allocation}

The mathematical programming models that we present here use mixed integer programming to minimise the deviation caused by the discrete nature of the seats to be allocated. Thus, the objective is to ensure that the percentage of the seats allocated is as close as possible to the actual percentage of votes received. All three approaches in this section were applied on the actual results of the 1999 and 2004 national elections in South Africa as verified by the Independent Electoral Commission [7, [8] $]$ For each election there was one national and nine provincial sets of votes, producing a total of 20 data sets. In the comparative case study that follows the seat allocations resulting from mathematical programming methods are compared to the LRMD, currently used by South Africa, as well as to the other popular methods used to allocate seats in other countries.

In general the absolute deviation $D_{i}$ for party $i$ is given by

$$
D_{i}=\left|\frac{v_{i}}{V}-\frac{s_{i}}{S}\right|
$$

where $v_{i}$ is the number of votes cast for party $i, V$ is the total number of votes cast, $s_{i}$ is the number of seats allocated to party $i$ and $S$ is the total number of seats.

\subsection{Minimisation of the maximum absolute deviation}

The principle behind this method is to minimise, over all parties, the largest deviation

$$
D_{\max }=\max _{i}\left\{D_{i}\right\}
$$

instead of the total deviation. This approach adopts has the same underlying philosophy as in the case of solving classical matrix games in game theory. The linear programming 
formulation is given by

$$
\min z=D_{\max }
$$

subject to

$$
\begin{aligned}
\left(\frac{s_{i}}{S}\right) 100-\left(\frac{v_{i}}{V}\right) 100 & \leq z \quad \text { for all } i=1, \ldots, P \\
\left(\frac{v_{i}}{V}\right) 100-\left(\frac{s_{i}}{S}\right) 100 & \leq z \quad \text { for all } i=1, \ldots, P \\
\sum_{i=1}^{P} s_{i} & =S \\
s_{i} & \geq 0 \text { and integer } \\
z & \geq 0,
\end{aligned}
$$

with all the symbols as defined earlier. The objective function minimises the maximum deviation. Constraint (9) calculates the deviation as the difference between the percentage of seats allocated and the actual percentage of the party's vote in the election. Constraint (10) calculates the deviation when the party's actual percentage is greater than the allocated percentage. Together these two constraints result in an absolute value for the deviation. Constraints (11) and (12) respectively ensure that the number of seats allocated does not exceed the available number of seats and that the number of seats allocated is indeed integers. A possible problem with this approach is that, although the maximum deviation is minimised, the total deviation can still be relatively large.

\subsection{Minimisation of total deviation}

A second approach, to counter the possible problem with the first approach, is to minimise the total deviation. Here we adopt a goal programming formulation, where a variable for the negative deviation $\left(\eta_{i}>0\right)$ and a variable for the positive deviation $\left(\rho_{i}>0\right)$ are introduced. The sum of both $\eta_{i}$ and $\rho_{i}$ is then minimised. The mathematical programming formulation is given by

$$
\min z=\sum_{i=1}^{P} \eta_{i}+\sum_{i=1}^{P} \rho_{i}
$$

subject to

$$
\begin{aligned}
\left(\frac{s_{i}}{S}\right) 100+\eta_{i}-\rho_{i} & =\left(\frac{v_{i}}{V}\right) 100 \quad \text { for all } i=1, \ldots, P \\
\sum_{i}^{P} s_{i} & =S \\
s_{i} & \geq 0 \quad \text { and integer } \\
z & \geq 0,
\end{aligned}
$$

where all the variables have the same meaning as in 4.1 . A possible problem that may arise in this formulation is that, although the total deviation is minimised, one party could potentially still incur a relatively large deviation. 


\subsection{Quadratic goal programming}

A quadratic goal programming model may be used to address the potential problems in the models presented in $\$ 4.1$ and $\$ 4.2$. In the quadratic programming approach the total deviation, as well as the sum of each party's deviation, is squared and weighted in the objective function. By taking the square, the model penalises the bigger deviations more than the smaller deviations and would thus avoid large deviations and minimise the total deviation at the same time. The mathematical programming formulation is given by

$$
\min v=w_{1} z^{2}+w_{2}\left(\sum_{i=1}^{P} \eta_{i}+\sum_{i=1}^{P} \rho_{i}\right)^{2}
$$

subject to

$$
\begin{aligned}
\left(\frac{s_{i}}{S}\right) 100+\eta_{i}-\rho_{i} & =\left(\frac{v_{i}}{V}\right) 100 & & \text { for all } i=1, \ldots, P \\
\eta_{i} & \leq z & & \text { for all } i=1, \ldots, P \\
\rho_{i} & \leq z & & \text { for all } i=1, \ldots, P \\
\sum_{i}^{P} s_{i} & =S & & \\
s_{i} & \geq 0 & & \text { and integer } \\
z & \geq 0, & &
\end{aligned}
$$

where $w_{1}$ and $w_{2}$ are the weights and the remainder of the variables have the same meaning as previously.

\section{A comparative case study for South Africa}

The mathematical programming approaches presented in the previous section were applied to the actual votes cast in South Africa. All three mathematical models yield the same result in all the data sets used. The 20 data sets used consist of the elections for 9 provincial governments and the national government in the 1999 [7] and 2004 [8] elections. The performances of the mathematical programming models (MPM) were tested for all the sets of data against that of LRMD and the other popular allocation methods. All three mathematical programming models gave exactly the same results for all the sets of data. The total absolute deviation was used as a measure to compare the mathematical models against the other methods. Similar results follow if other measures available in the literature, such as the Rae index, Loosemore-Handy index, least squares or maximum deviation [10, 13] are used instead. A method with a lower total absolute deviation is thus considered to yield a better seat allocation than a method with a higher total absolute deviation. The total absolute deviations for the seat allocations resulting from the different allocation methods for all the voting districts participating in the 1999 and 2004 national elections in South Africa are summarised in Tables 6 and 7 . The same results are demonstrated graphically in Figure 3.

In all cases the total absolute deviation of the mathematical models was less than or equal to that of LRMD (see Figure 3). Additionally, as shown in Tables 6 and 7 , the 


\begin{tabular}{lrrrrrr}
\hline District & MPM & LRMD & H & SL & MSL & LRMH \\
\hline National & 1.078 & 1.078 & 2.546 & 1.078 & 1.419 & 1.078 \\
Eastern Cape & 3.498 & 3.498 & 7.732 & 3.498 & 5.507 & 3.498 \\
Free State & 11.444 & 12.686 & 19.535 & 12.686 & 16.196 & 11.444 \\
Gauteng & 4.551 & 4.551 & 12.384 & 4.689 & 4.689 & 4.551 \\
KwaZulu-Natal & 3.894 & 3.894 & 7.530 & 7.530 & 5.030 & 3.894 \\
Mpumalanga & 11.984 & 11.984 & 22.818 & 14.796 & 14.796 & 11.984 \\
Northern Cape & 10.371 & 11.423 & 19.543 & 11.423 & 14.652 & 10.371 \\
Northern Province & 7.498 & 8.098 & 19.342 & 8.098 & 10.302 & 7.498 \\
North West & 10.342 & 10.342 & 20.767 & 13.183 & 13.183 & 10.342 \\
Western Cape & 6.662 & 6.662 & 17.643 & 8.119 & 8.119 & 6.662 \\
\hline Total & 71.322 & 74.216 & 149.84 & 85.1 & 93.893 & 71.322 \\
\hline
\end{tabular}

Table 6: The total absolute deviations for the allocation of seats using mathematical programming and the different allocation methods for the results of the South African election in 1999. The following abbreviations are used: MPM for mathematical programming models, LRMD for Largest remainder method using a Droop quota, $H$ for d'Hondt's method, SL for Sainte-Laguë's method, MSL for modified Sainte-Laguë's method and LRMH for largest remainder method using a Hare quota.

mathematical programming models yield a smaller total absolute deviation than all of the other allocation methods mentioned in this paper, with one exception (namely LRMH), where they give the same deviation. It is worth mentioning that the LR method using the Hare quota yielded the exact same seat allocation as the mathematical programming models for the 1999 and 2004 national elections in all 9 provinces as well as for the national seating. In Table 8 a summary is provided where all the allocation methods were applied to the votes cast in the Free State province during the 2004 elections. Due to the fact that all the mathematical programming models arrive at the same seat allocation, only one set of results is given to represent all three models.

It may be seen in Table 8 that some methods favour the more popular parties and some favor the less popular parties. These figures tend to support the theory that the d'Hondt and Modified Sainte-Laguë methods are more biased towards the larger parties [11, 14]. Seat allocations based on the Sainte-Laguë and LRMD methods yield better proportional representation, but it is the LR method using the Hare quota and the mathematical programming models that give the lowest overall total absolute deviation. Hence, these last two models are the fairest for this example. This pattern repeats itself in all the other provinces as well. These results are in line with the findings of similar experimental studies done elsewhere in the world [9, 14].

Another interesting pattern (see Figure 3) that arises for this data set is that the total absolute deviation increases as the number of seats decreases. In the study by Schuster et al. 2003) the same result is experimentally and formally deduced if the Hare quota, instead of the Droop quota, is used. 


\begin{tabular}{lrrrrrr}
\hline District & MPM & LRMD & H & SL & MSL & LRMH \\
\hline National & 1.531 & 1.533 & 3.008 & 2.464 & 1.964 & 1.531 \\
Eastern Cape & 5.406 & 7.092 & 10.855 & 5.406 & 9.052 & 5.406 \\
Free State & 11.4 & 14.04 & 18.17 & 14.04 & 18.17 & 11.4 \\
Gauteng & 4.069 & 5.05 & 11.11 & 4.07 & 6.68 & 4.069 \\
KwaZulu-Natal & 4.781 & 4.781 & 10.327 & 5.949 & 9.113 & 4.781 \\
Mpumalanga & 9.801 & 11.87 & 13.99 & 13.99 & 13.99 & 9.801 \\
Northern Cape & 8.805 & 8.805 & 15.672 & 11.91 & 13.521 & 8.805 \\
Limpopo & 5.256 & 7.16 & 12.933 & 7.16 & 9.614 & 5.256 \\
North West & 8.835 & 11 & 13.271 & 13.271 & 13.271 & 8.835 \\
Western Cape & 8.164 & 9.181 & 15.68 & 9.181 & 9.181 & 8.164 \\
\hline Total & 68.048 & 80.512 & 125.016 & 87.441 & 104.556 & 68.048 \\
\hline
\end{tabular}

Table 7: Total absolute deviation for the allocation of seats using the mathematical programming models and the different allocation methods for the results of the South African election in 2004. For the abbreviations used refer to Table 6 .

\section{Conclusion and ideas for further study}

In this paper various methods for the allocation of seats in a PR election system were reviewed. The objective in each is to minimise, for each party, some measure of the deviation between the actual percentage of votes received and the percentage of seats allocated to that party. This objective served as a criterion to ascertain whether any fair allocation methods exist. Two categories of allocation methods, namely highest average methods and largerst remainder methods, were discussed. New mathematical programming approaches were also introduced by the authors and compared to other existing methods. These new methods were constructed with the specific objective of minimising the above-mentioned deviation. All in all, six methods were investigated in a comparative case study based on actual election results from South Africa's past two elections.

Currently, South Africa uses the LRMD. For this method it was proved that, in general, the potential number of seats allocated from the remainders increases as the number of parties increases. Additionally, a second theorem shows that the number of votes not used to allocate seats (i.e. "lost votes") increases with an increase in the number of parties. Results from simulations supported these theorems. The implication of these theorems is that an increase in the number of parties will definitely lead to an increase in lost votes. This fact leads to the conclusion that an increase in the number of parties leads to an increase in the total absolute deviation, which is also supported by the simulation runs. An increase in the number of political parties thus leads to an increase in the disproportionality. Moreover, an increase in the number of parties leads to more votes not counting towards seat allocation. From a fairness point of view, a decrease in the number of parties will lead to a more fair allocation.

In the comparative case study, where the seat allocations of six models were compared to each other, the mathematical programming models yielded the lowest total absolute deviation out of all the allocation methods, as expected (with the exception of LRMH which produced the same deviation). This result indicates that relatively simple OR methods may be used to determine more fair allocations than the current methods used 


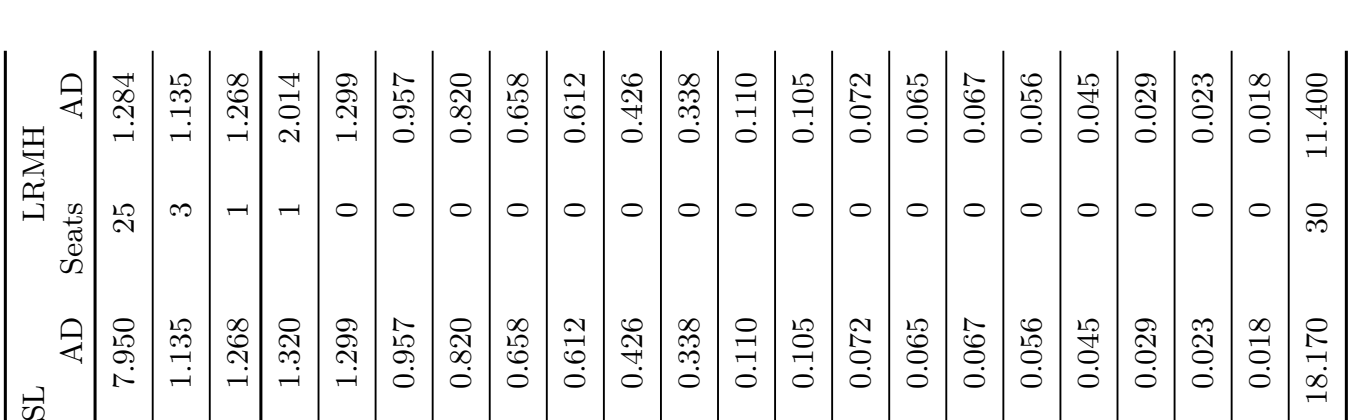
$\sum^{\circ}$

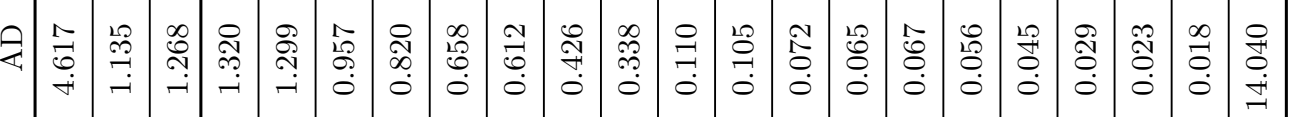
穴

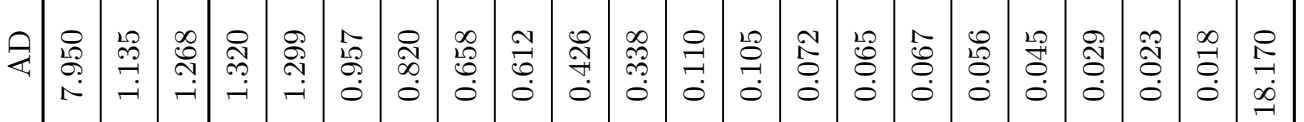
I

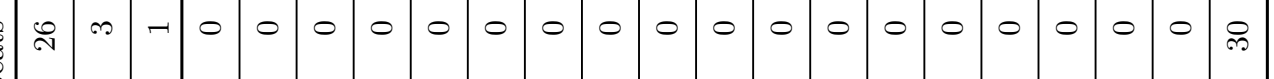

茓 ลิ

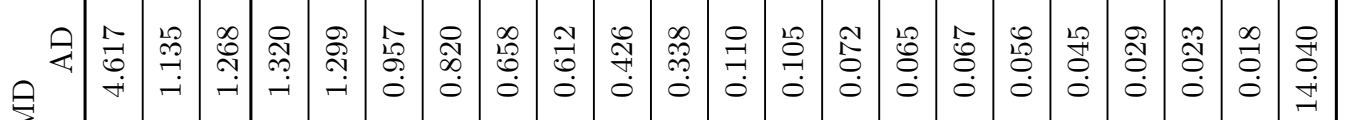

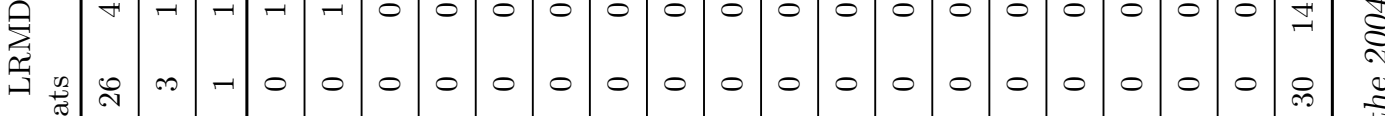

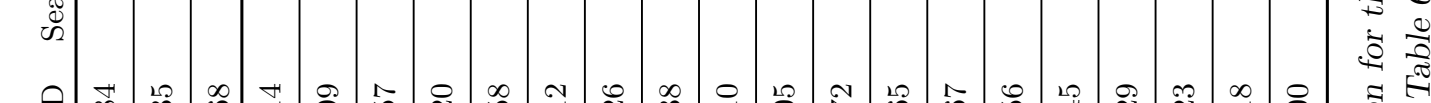

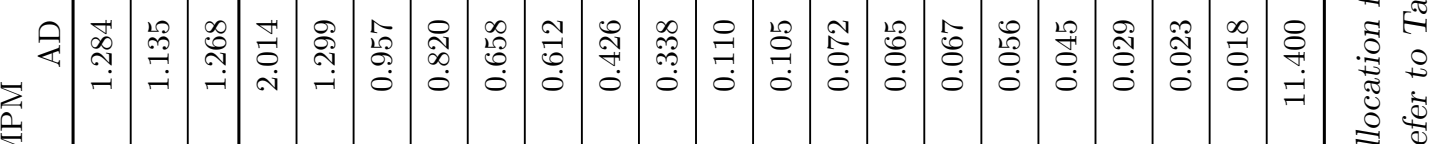

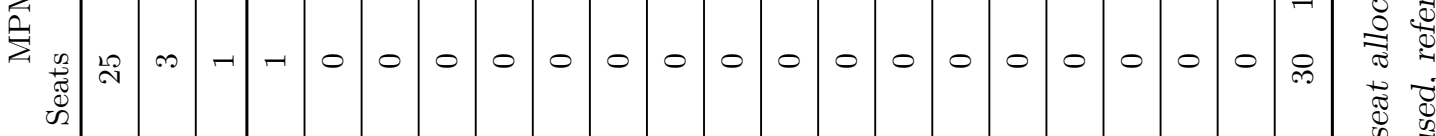

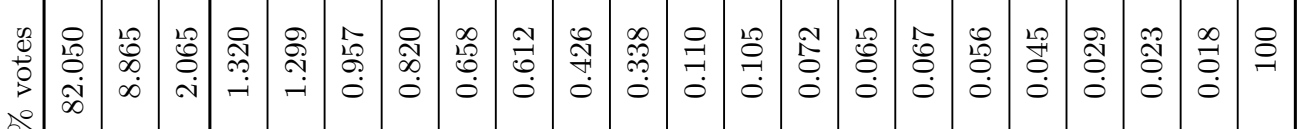

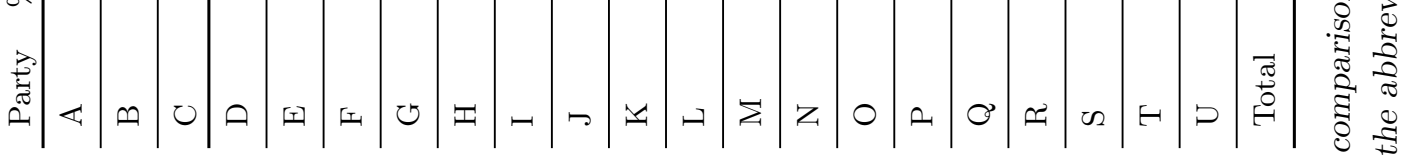

$\varangle \breve{6}$

$\ddot{\infty} \frac{\dot{s}}{\sigma}$ 


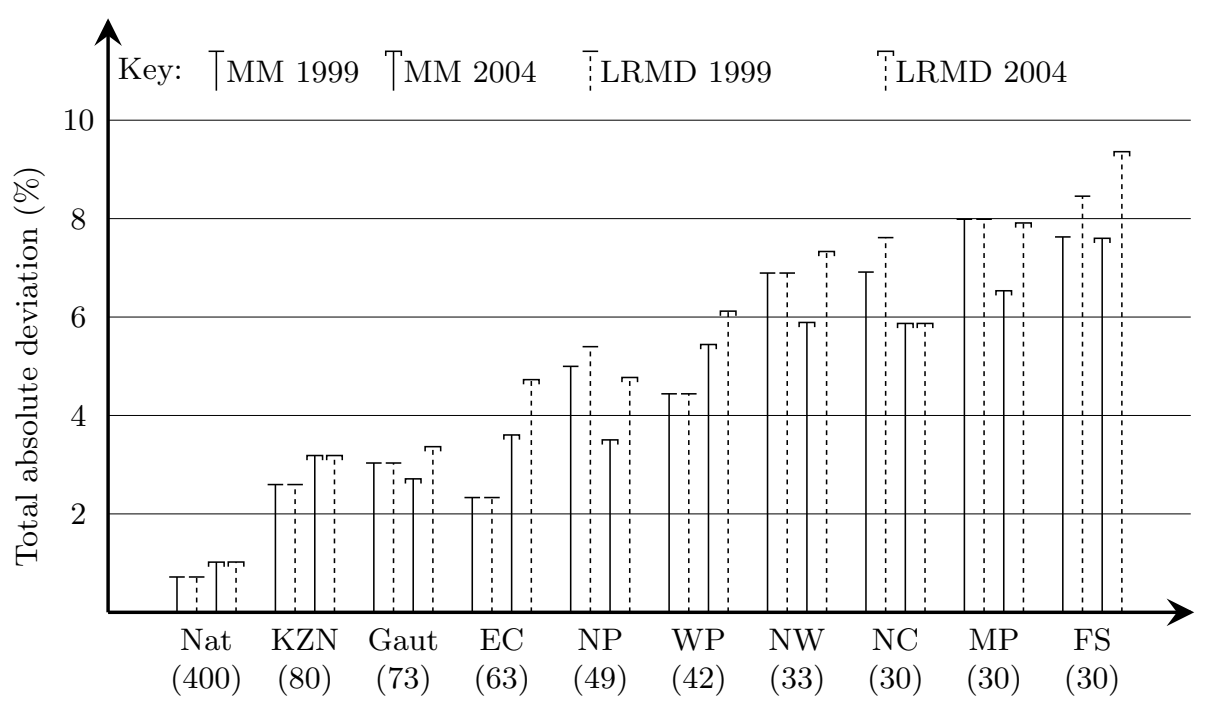

Figure 3: The total absolute deviation (as a percentage) for the allocation of seats using mathematical programming and LRMD. The data for the 1999 and 2004 elections in South Africa were used. The value in brackets is the total number of seats that must be allocated for that region. The following abbreviations are used: Nat for national, KZN for KwaZulu Natal, Gaut for Gauteng, EC for Eastern Cape, NP for Northern Province (Limpopo), WP for Western Cape, NW for North West, NC for Northern Cape, MP for Mpumalanga and FS for Free State.

around the world. This study also indicated that the largest remainder method using the Hare quota yields the best seat allocations in the South African context and does outperform the LRMD that is currently in use.

Previous studies indicated that not all methods are unbiased. Some methods, such as those of d'Hondt and the Modified Sainte-Lague, amongst others, tend to be biased towards the more popular parties. The results of the comparative study support this conjecture. The nature of South Africa's current political situation is that there is one dominant party, which logically will receive the most seats. It is therefore in the smaller parties' best interest to have an unbiased allocation system, where they deserve their fair share of representation. In this study only one measure of fairness was used, namely total absolute deviation. If a method is not fair, it implies that some parties are favoured more and others are harmed more. This raises the question of how biased certain methods are. The question arising from this study is how sensitive the bias of allocation methods is to (i) the number of parties involved and (ii) the relative sizes of the parties. This question leaves an opportunity for further investigation and studies on this topic.

\section{References}

[1] Amy DJ, How proportional representation elections work: PR library, [Online], [Cited: 12 August 2005], Available from http://www.mtholyoke.edu/ acad/polit/damy/BeginnningReading/howprwor.htm 
[2] Center FOR VOting AND Democracy, What is proportional representation?, [Online], [Cited: 4 August 2005], Available from http://www.worldpolicy.org/ globalrights/democracy/abcs.html

[3] Electoral act 73 of 1998, 1998, [Online], [Cited: 12 August 2005], Available from http://www.elections.org.za/Documents/iec-a6_act.pdf

[4] Electoral Task Team Review Roundtable, 2003, Electoral models for South Africa: Reflections and options, [Online], [Cited: 8 November 2005], Available from http://www.kas.org.za/Publications.asp

[5] ERnst LR, 1994, Apportionment methods for the house of representatives and the court challenges, Management Science, 40(10), pp. 1207-1227.

[6] Geys B, 2004, Proportional representation, political fragmentation and political decision-making: An economic analysis, $\mathrm{PhD}$ dissertation, Vrije Universiteit Brussel, Brussels.

[7] Independent Electoral Commission, 1999, National 8 Provincial elections '99, [Online], [Cited: 12 August 2005], Available from http://www.elections.org.za/ results/elections99.asp

[8] Independent Electoral Commission, 2004, National \& Provincial elections 2004, [Online], [Cited: 12 August 2005], Available from http:// www.elections.org.za/results/elections2004_static.asp

[9] Lijphart A, 1994, Electorial systems and party systems: A study of twenty-seven democracies, 1945 - 1990, Oxford University Press, Oxford.

[10] NÁvrat P, 2003, Comparative study of electoral systems and their features, Foundation for democratic reforms, Hyderabad, Czech Republic. Available from: www. loksatta.org/esystems.pdf

[11] O'Leary B, Grofman B \& Elklit J, 2005, Divisor methods for sequential portfolio allocation in multi-party executive bodies: Evidence from Northern Ireland and Denmark, American Journal of Political Science, 49(1), pp. 198-211.

[12] Oyama T \& ICHIMORI T, 1995, On the unbiasdness of the parametric divisor method for the apportionment problem, Journal of the Operations Research Society of Japan, 38(2), pp. 301-321.

[13] Pennisi A, 1998, Disproportionality indexes and robustness of proportional allocation methods, Electoral Studies, 17(1), pp. 3-19.

[14] Schuster K, Pukelsheim F, Drton M \& Draper NR, 2003, Seat biases of appointment methods for proportional representation, Electoral Studies, 22, pp. 651676.

[15] Wikipedia, the free Encyclopedia, 2005, De Hondt method, [Online], [Cited: 4 August 2005], Available from http://en.wikipedia.org/wiki/D'Hondt_method 
[16] Wikipedia, THE FREE ENCYClOPEDIA, 2005, Largest remainder method, [Online], [Cited: 4 August 2005], Available from http://en.wikipedia.org/ wiki/Largest_remainder_method

[17] Wikipedia, the Free EnCyClopedia, 2005, Sainte-Laguë method, [Online], [Cited: 4 August 2005], Available from http://en.wikipedia.org/ wiki/Sainte-Lagu\%C3\%AB_method 